\title{
New Opportunities for Metals Extraction and Waste Treatment by Electrochemical Processing in Molten Salts
}

\author{
Donald R. Sadoway \\ Department of Materials Science and Engineering \\ Massachusetts Institute of Technology \\ Cambridge, Massachusetts 02139-4307
}

\begin{abstract}
Molten salt electrolysis is a proven technology for the extraction of metals -- all the world's primary aluminum is produced in this manner. The unique properties of molten salts also make them excellent media in which to treat a variety of forms of waste. Of special note in this regard is electrolysis in molten oxides, a concept put forward by the author, initially as a "clean technology" for producing primary metal. However, in the context of waste treatment, electrolysis in molten oxides is a process offering the prospect of changing the valence of dissolved heavy metals while making pure oxygen gas as the main by-product. Laboratory tests conducted at a temperature of $1550^{\circ} \mathrm{C}$ on chromate sludge dissolved in an melt composed of $\mathrm{Al}_{2} \mathrm{O}_{3}, \mathrm{SiO}_{2}, \mathrm{CaO}$, and $\mathrm{MgO}$ have confirmed electrochemical production of oxygen on a carbon-free anode.
\end{abstract}

\section{Introduction}

Molten salt electrolysis is the electrolytic decomposition of a compound dissolved in an ionic melt. The prime example of this process can be found in the production of aluminum. The compound, alumina $\left(\mathrm{Al}_{2} \mathrm{O}_{3}\right)$, derived from the mineral bauxite, is dissolved in an ionic melt comprising a multicomponent solution of cryolite $\left(\mathrm{Na}_{3} \mathrm{AlF}_{6}\right)$, aluminum fluoride $\left(\mathrm{AlF}_{3}\right)$, and calcium fluoride $\left(\mathrm{CaF}_{2}\right)$. The products of electrolysis are molten aluminum and carbon dioxide, the latter due to the attendant consumption of the carbon anode. Primary aluminum is produced in a reactor known as the Hall cell. ${ }^{1}$ Alternatively, the compound undergoing electrolytic decomposition can be derived from waste. Processing in molten salts, with their capacity to dissolve materials to very high concentrations compared to those attainable in aqueous solutions, can be rather advantageous. High solubilities lead to high limiting current densities, and this, in turn, results in high productivities. For a primer on molten salt electrolysis and a review of the basic literature in the field of molten salts the reader is directed to an earlier publication of the author (1).

\section{The Need for New Metallurgical Technology}

The conversion of iron ore to finished steel is both energy intensive and capital intensive and as a result efforts at improving the process have up to now been focused primarily on reducing operating costs through increases in efficiency. More recently, attention has begun to shift towards the environmental aspects of iron and steelmaking largely in order to attempt to comply with stricter

1 The extraction of aluminum by the electrolysis of alumina was invented in 1886 independently by Charles Martin Hall in the U.S. and by Paul Héroult in France. The reactor for this process is known as the Hall cell in North America and as the Hall-Héroult cell in Europe. 
regulations, e.g., the Clean Air Act amendment of November 15, 1990 which targets coke ovens for closure. Today's steelmaking technology, comprising the three main unit operations of coke making, reduction in the blast furnace, and oxidation of excess carbon the basic oxygen furnace, has enormous environmental consequences. The by-products of coke making include volatile organic compounds and carbon monoxide, as well as particulate emissions (2). The blast furnace byproducts include flue dust, slag, and vast quantities of carbon dioxide (2). The basic oxygen furnace produces large amounts of carbon monoxide which must be combusted before venting to the atmosphere (2). Industrial carbon contains sulfur with the result that $\mathrm{SO}_{2}$ issues both from coke ovens and from blast furnaces. The only concerted effort at the moment in this country to develop new steelmaking technology is the AISI Direct Steelmaking Program supported jointly by industry through the American Iron and Steel Institute (AISI) and government through the congressional Steel Initiative administered by the Department of Energy. The technical objective of that project is to combine the functions of the coke oven and the blast furnace in one unit operation so that smelting takes place in a single reactor where iron oxide and coal are both charged into the same melt or bath (hence the name, "in-bath smelting"). While it addresses some of the problems associated with emissions from coke ovens, in-bath smelting is intrinsically incapable of dealing with the larger problem of greenhouse gas emissions from steelmaking because both conventional technology and in-bath smelting require that effectively the same amount of carbon be used to reduce a given amount of iron oxide. Clearly, from a broader environmental perspective, one must look at totally new strategies for extracting metal without the use of carbon.

Conventional wisdom has it that there are two carbon-free alternatives to current steelmaking technology: direct reduction with hydrogen and electrolytic extraction from aqueous solution $(3,4)$. Safety considerations make hydrogen unattractive $(4)$, while aqueous electrolysis suffers from very low productivity, i.e., poor space/time yield (3). To address these shortcomings the author advocates a new process for the production of steel: iron oxide dissolved in a molten oxide solution is electrolytically decomposed to make pure liquid iron and oxygen gas $(5,6)$. Molten oxide electrolysis has been tried in the past, but relied on the use of carbon anodes which are consumed in the process thereby generating carbon monoxide and carbon dioxide as byproducts (7). Thus, the discovery of an inert anode is critical in enabling the electrolytic recovery of iron from a molten oxide electrolyte without generation of by-product $\mathrm{CO} / \mathrm{CO}_{2}$. Under such conditions, electrolytic steelmaking possesses distinct advantages over conventional technology. There is no need for coke ovens, blast furnaces and BOF's. This eliminates the production of the effluents cited above. Furthermore, as the main source of sulfur in steel is the sulfur contained as an impurity in industrial carbon, the absence of process carbon means that electrolytic steel contains no sulfur.

There are other advantages. The high solubility of iron oxide in molten oxides will result in very hugh space-time yields, i.e., very high productivity which is directly related to the current density of the electrolysis cell. In the electrolytic production of aluminum, the Hall cell operates at a current density of approximately $1 \mathrm{~A} / \mathrm{cm}^{2}$. This limit is imposed on the process by the fact that the concentration of aluminum oxide must be kept at a value of about $1 \%$. In the electrolytic production of steel in a molten oxide electrolyte it is expected that the concentration of iron oxide will be between 10 to $20 \%$. Since the limiting current density scales directly with concentration, this means that we can expect such melts to sustain current densities of 10 to $20 \mathrm{~A} / \mathrm{cm}^{2}$ ! These are production rates far beyond anything in contemporary electrolytic technology, including the most 
modern aluminum plants. Such a dramatic increase is possible owing to the choice of electrolyte chemistry, which has never been employed in the metals industry. The fact that these remarkable productivities can be achieved in an ecologically sound manner demonstrates that environmental conservancy and commercial profitability need not be at cross purposes. The production of stainless steel is an example of the case in point.

Direct electrolysis is particularly suited for the production of stainless steel. In fact, even with today's economics which favor the indiscriminate use of process carbon, i.e., carbon as a chemical reagent, electrolytic production of stainless steel looks attractive. Consider the production of a master alloy consisting of 80 weight percent iron and 20 weight percent chromium. This would serve as the starting point for both the 300 series stainless steels, to which one would add nickel, as well as to the 400 series stainless steels. The table below shows the results of calculations performed on the basis of an electrolysis cell modeled on the Hall cell which produces aluminum: that is to say, monopolar electrodes, liquid metal cathode on the bottom, solid anode on the top, operating at an energy efficiency of approximately $35-40 \%$. A worst case scenario was chosen in which all electricity was made in coal-fired generators. A conversion of 26 million BTU's per ton of coal to yield $2,400 \mathrm{kWh}$ of electricity was used in the calculations.

Estimated Energy Consumption and Environmental Impact:

Direct Electrolysis $v s$. Existing Process

Energy (kWh/lb metal) Process Carbon (lb carbon/lb metal) Electrolysis Existing Electrolysis Existing

$\begin{array}{lllll}\text { ferrochromium } & 1.5 & 1.9 & \sim 0 & 0.75\end{array}$

$(80 \% \mathrm{Fe}-20 \% \mathrm{Cr})$

These numbers show that if one were to make iron-chromium by direct electrolysis of the appropriate amounts of both chromium oxide and iron oxide, the estimated energy requirement is $1.5 \mathrm{kWh} / \mathrm{lb}$ metal. When one compares this to the preparation of the same iron-chromium alloy by conventional technology, i.e., mixing steel scrap with ferrochromium produced in an electric arc furnace, the estimated energy requirement is $1.9 \mathrm{kWh} / \mathrm{lb}$ metal. Clearly, these results favor direct electrolysis. Furthermore, conventional technology uses a considerable amount of carbon, about 0.75 pounds per pound of metal product. Direct electrolysis requires effectively no process carbon. Direct electrolysis has other advantages over conventional technology. Consider that the ferrochromium produced in an electric arc furnace contains on the order of 5 weight percent carbon! This must be removed by treatment in subsequent unit operations, such as argon degassing, which cannot fully remove the carbon. This is due to the fact that in stainless steel carbon cannot be removed below a certain concentration without loss of chromium. For this reason, it is very difficult to produce an ultra-low carbon stainless steel. In contrast, direct electrolytic steelmaking, as described herein, requires no carbon, and therefore produces a liquid metal product that is virtually carbon-free and, hence, sulfur-free. In the stainless steel business today, there is a great effort to find ways to reduce carbon content, as metallurgists agree that high performance can be expected when one obtains low levels of interstitial impurities such as carbon and nitrogen. In the 
making of stainless steel, direct electrolysis has the intrinsic capability to meet these specifications in a way that conventional stainless steel technology cannot on a cost-competitive basis. This takes into account the fact that, in direct electrolytic steelmaking, fewer unit operations are necessary to make high purity ferrochromium compared with the combined remelting, alloying, and electric arc furnace operations currently practiced. Finally, the carbon arc furnace uses carbon electrodes which are consumed in the making of ferrochromium and generate $\mathrm{CO} / \mathrm{CO}_{2}$ plus fume and particulates. Direct electrolysis completely avoids producing these offensive by-products and thereby reduces waste at source.

Why has no one exploited molten oxides as electrolytes in the past? Three reasons. First, cost. Carbon is cheap, and there is virtually no penalty associated with venting $\mathrm{CO}_{2}$ to the atmosphere. Secondly, the database is inadequate. There is very little information in the literature on the physicochemical properties of molten oxides. Thirdly, there are formidable materials problems associated with the principal elements of an electrolytic cell. What are to be the materials of construction of the anode, cathode, and cell wall? In previous work associated with attempting to discover a carbon-free anode for use in the electrolytic production of aluminum the author has developed a methodology for tackling such materials problems (8).

Figure 1 shows a sketch of a first-generation electrolytic steelmaking cell, modeled after the Hall cell. An electrolysis cell is a device designed to permit electrical energy to perform chemical work. This occurs by the transfer of electrical charge between two electrodes across an ionically conducting liquid (electrolyte). The electrolyte in this system is a multicomponent solution consisting of iron oxide and other oxides, such as silica and calcia. The cathode is a pool of molten iron at the bottom of the cell. At the interface of liquid metal and electrolyte, the electrochemical reduction of iron occurs according to the following reaction:

$$
\mathrm{Fe}^{2+}(\text { electrolyte })+2 \mathrm{e}^{-} \text {(cathode) ---> Fe (liquid) }
$$

The origin of the $\mathrm{Fe}^{2+}$ is the iron oxide feed, which has dissolved in the molten oxide electrolyte and dissociated to form $\mathrm{Fe}^{2+}$ cations and $\mathrm{O}^{2-}$ anions. The liquid iron produced is instantly incorporated into the metal pool without the need for mass transport to another site within the cell. Thus, as reaction proceeds, the depth of the iron pool increases. The solid member forming the floor of the cell and also acting as current collector must be made of a material that is chemically inert in contact with molten iron and also a good electronic conductor. Materials satisfying these requirements include certain electronically conducting oxides and refractory hard metals, as well as thermally graded materials such as "cold fingers" around which iron has frozen. At the top of the cell is the anode, which acts as current feeder. The anode must be chemically inert in order to support the evolution of oxygen, which occurs according to the following reaction:

$$
\mathrm{O}^{2-} \text { (electrolyte) ---> 2e (anode) }+1 / 2 \mathrm{O}_{2} \text { (gas) }
$$

The source of $\mathrm{O}^{2-}$ is the iron oxide feed which has dissolved and dissociated in the molten oxide electrolyte. The anode becomes an electron sink, and the product oxygen gas evolves as bubbles on the surface of the anode and floats to the surface of the melt. Candidate anode materials include electronically conducting oxides. The sidewall consists of electrolyte frozen against a shell made of refractory brick. This is the electrolytic equivalent of skull melting, and is precisely the condition in 
a modern Hall cell producing tonnage aluminum. Feed consisting of iron oxide and (optionally) chromium oxide is added to the cell from the top. The process is continuous. Metal is removed from the cell by syphoning periodically.

To summarize, then, electrolytic steelmaking has the following attributes:

* completely eliminates the need for carbon in the process

* environmentally benign - no $\mathrm{CO}_{2}$, no $\mathrm{SO}_{2}$, no coke ovens

* less capital intensive than conventional steelmaking technology - fewer unit operations

* requires less energy than conventional technology for the production of stainless steels and most specialty steels

* produces high-purity liquid metal, carbon-free and sulfur-free. Such steels have superior performance.

* continuous process. Conventional steelmaking technology, consisting of coke ovens, blast furnace and BOF (basic oxygen furnace), is a series of batch processes.

* is based on a technology with which the metals industry is familiar - molten salt electrolysis

In order to provide the scientific underpinnings of a new process for electrolytic steelmaking the physical chemistry of various molten oxides is under study. These oxides are candidate electrolytes for such a process because they meet the following requirements:

oxide

* they are excellent solvents for transition-metal oxides such as iron oxide and chromium

* they dissociate to form ions. In order to conduct electrolysis in a medium it must be an ionic conductor. Silicates are unsuitable as their melts are covalent. Transition-metal oxides are unsuitable as their melts behave as semiconductors with an unacceptable high level of electronic conduction. This shunts ionic conduction and disconnects faradaic processes at the electrodes.

* they have relatively low vapor pressures even at the necessarily high temperatures for producing liquid metal

* they are non-toxic and present no major health risk in industrial use or in disposal

What are the problems? Why is there any uncertainty? Because molten oxides have never been used for the electrolytic extraction of metals, there have been very few studies of this class of liquids from the perspective of electrochemical processing. The work on steelmaking slags and welding fluxes for the most part lies outside the electrolytic domain of composition. As a result, the database is seriously deficient. One must first verify that molten ferrochromium-bearing oxides (ferrochromates) behave as electrolytes, i.e., as ionic conductors. In addition to knowing the electrical properties of liquid $\mathrm{FeO}_{\mathrm{x}}-\mathrm{CrO}_{\mathrm{y}}$ and solutions containing them, one must know the relative chemical reactivities of elements found in chromate sludge and in candidate supporting electrolytes. This requires a knowledge of the solution thermodynamics. Systematic investigation of the physical chemistry of molten oxides is currently underway in the author's laboratories.

\section{Direct Electrolysis of Molten Oxides: The Concept}

The broader case for electrolytic extractive metallurgy can be made as follows. Almost all 
conventional molten salt electrolytic technologies use halide electrolytes and carbon anodes. There are attendant environmental consequences associated with each. As a "clean" alternative, the author has advocated the use of molten oxide electrolytes and carbon-free anodes $(9,10)$. This allows one to use metal oxide feed and obviates the need for chlorination or fluorination in order to prepare suitable cell feed, hence the designation direct electrolysis. Direct electrolysis of molten oxides is the electrolytic decomposition of a metal oxide into molten metal and oxygen gas. With reference to resource recovery, direct electrolysis has enormous potential. The metal oxide feedstock can be "concentrate" derived from ore in which case direct electrolysis makes virgin metal or the metal oxide feedstock can be metallurgical or chemical waste in which case direct electrolysis is nothing less than a process for waste treatment and recycling. The process uses carbon-free electrodes; this both avoids the need for energy intensive carbon electrode manufacture and guarantees the absence of greenhouse gas emissions as the by-product of the metal recovery step. Feeding the electrolysis cell and harvesting the products can be done in such a way as to allow continuous operation. The concept applies to a variety of chemistries including titanium, ferroalloys (including stainless steel), rare earth metals, and uranium. The process in its various embodiments by necessity operates at temperatures higher than those found in any of the contemporary electrolytic technologies -- oxides have higher melting points than halides) and has been alternately termed pyroelectrolysis.

The need for direct electrolysis can be addressed from both perspectives: the primary extraction of virgin metal from ore and remediation of metallurgical and chemical waste. Each has its own peculiarities although they both involve improved energy utilization.

First, metals extraction. The extraction, refining, and recycling of metals involve processes that are energy intensive. In addition, such processes are typically resource intensive, capital intensive and produce a host of by-products that are far from ecologically benign. For the most part, the extraction processes in place today were developed many years ago (the iron blast furnace and the aluminum electrolysis cell are both over 100 years old) in an industrial environment that is substantially different from that of today. For example, at the time of inception of these processes, energy was cheap, as was the cost of capital. There were almost no environmental regulations to comply with, nor was there the threat of legal action against companies for practices that harmed the health and safety of their workers. As a result, much of contemporary metallurgy is based upon intensive use of carbon, either as a chemical reductant or in the form of an electrode: either way, this nonrenewable resource is consumed in the process. To make a ton of steel requires about $1 / 2$ ton of carbon as coke. To make a pound of aluminum requires about $1 / 2$ pound of carbon as a consumable anode. The preparation of industrial carbon itself is an energy intensive process. Coke making and electrode manufacture require energy and generate a host of toxins. There is still another important consequence associated with the use of carbon. Industrial carbon contains sulfur as an impurity. This sulfur either issues as sulfur dioxide (acid rain) or reports to the metal product contaminating it (failure to meet product specification). To treat the $\mathrm{SO}_{2}$ emissions and to refine sulfur out of the metal consumes energy, increases operating costs, and through the need for more unit operations, increases capital costs.

Secondly, remediation of metallurgical and chemical waste. Much of the solid industrial waste in this country is in the form of oxidized metal, some of which is water soluble and thus poses a threat to the environment. We now face the enormous task of treating this stuff to make it chemically inert. The energy required to do so is staggering. What is lacking are processes that are 
not only energy efficient but also have acceptable productivity, i.e., space/time yield. As one example, chromate sludge contains water soluble hexavalent chrome. Pyroelectrolysis in molten oxides has the capability to reduce hexavalent chrome and recover the iron and chromium metal contents of this material which in many cases exceed those found in the richest ore bodies in this country! In other words the value of the metal produced could pay for the remediation if this metal were recovered.

As mentioned above, direct electrolysis in molten oxides has been tried in the past but relied on the use of carbon anodes (7). What distinguishes the present embodiment is the absence of carbon. This is critical to the successful implementation of the concept. The author has studied the problem of finding a carbon-free nonconsumable anode for use in aluminum electrolysis cells. One of the results of this work has been the development of a methodology for materials selection and testing $(8,11)$. This methodology is rather general and has provided insights about materials problems far beyond the confines of the aluminum cell. The methodology is based upon a systems view of the process and therefore takes into full consideration the types of chemical reactions that occur between the key elements of the cell (cathode, anode, sidewall) and the electrolyte and cell products. A fresh look at the use of molten oxides as electrolyte media for metal recovery in the light of the above cited methodology gave birth to the concept of carbon-free direct electrolysis. Among the foundations of the new concept is the recognition that at high temperatures certain oxides themselves are electronic conductors and can serve as anodes, e.g., ferrites and titanates. At the same time, the melts of these same oxides are not necessarily electronic, but rather can be modified by forming multicomponent solutions with appropriate solvents so as to make ionic liquids capable of sustaining faradaic processes.

The potential applications of direct electrolysis are manifold both for metals extraction and treatment of waste. Candidate metals include titanium, ferroalloys (ferrochromium and ferromanganese), rare-earth metals, and iron (steel). Estimates suggest that the price of titanium could be cut by as much as $50 \%$ thanks to higher processing efficiency, notably reduced energy consumption: $16 \mathrm{kWh} / \mathrm{lb}$ by current technology versus $6 \mathrm{kWh} / \mathrm{lb}$ by direct electrolysis. No one makes virgin stainless steel -- all stainless is made by alloying ferrochromium (made in a carbon arc furnace) with steel scrap (melted in an electric arc furnace fitted with carbon electrodes). Direct electrolysis has the capacity to convert a mixed oxide feed of iron and chromium oxides into virgin stainless of very high quality (ultralow carbon and sulfur) and to do so using less energy than the current technologies. Manganese has remarkable properties in terms of mechanical behavior and corrosion resistance. Unfortunately, current manganese extraction technologies yield a brittle product due to the presence of unacceptably high levels of harmful contaminants, notably interstitials such as carbon. Direct electrolysis is capable of making high-purity, ultralow-carbon manganese with which one could design an entire array of high-performance alloys. Applications of direct electrolysis to treatment of waste will be described below.

\section{Processing of Waste by Molten Salt Electrolysis}

Exploratory research has been conducted in this laboratory to assess the viability of processing chromate sludge by electrolysis in melts composed of oxides as distinct from the melts traditionally employed in industrial molten salt electrochemistry, namely chlorides and fluorides. The work has been described in a recent publication, portions of which are reproduced here for the 
convenience of the reader (12). Secondary residue or waste mud produced in the course of chromate chemical production is the focus of attention in this work. The goal is to reduce the water soluble hexavalent chromium either to insoluble trivalent chromium or to chromium metal. The use of an oxide melt for the electrolyte establishes the conditions for the production of oxygen gas as the anodic reaction. This is very attractive from an environmental standpoint where the cost of treating byproducts can be a deciding factor in determining the profitability of a process.

\section{A. Treatment of Chromate Sludge}

Chromate residue, like much of the solid industrial waste in this country, is in the form of oxidized metal, some of which is water soluble and thus poses a threat to the environment. Treating this stuff to make it chemically inert is an enormous task. The New Jersey Department of Environmental Protection estimates that there is over 3,000,000 tons of chromate sludge in some 160 sites in Hudson County (13). Remediation technologies must not only be energy efficient but also have acceptable productivity, i.e., space/time yields. One practice is to leach out the hexavalent chromium for subsequent electrochemical treatment. This requires vast quantities of water, and one cannot be certain of the extraction efficiency of the leaching operation. Molten salt electrolysis in a fused oxide electrolyte can be viewed as a potential alternative to the aqueous chemistry cited here. The high-temperature approach not only may reduce hexavalent chromium but also may recover the iron and chromium metal contents of the waste material. In special circumstances the value of the metal so produced may even offset the cost of remediation. The chromate sludges found in New Jersey contain chromium oxide at levels around 2 weight per cent and iron oxide at levels around 25 weight per cent.

These are the key issues in the relevant high temperature physical chemistry as they apply to treatment of chromate residue. Are chromate bearing melts ionic or is there an unacceptably high level of electronic conduction, i.e., what is the electrical conductivity of multicomponent chromate melts as a function of temperature and composition? The answer helps assess the technical viability of the concept (including the energy consumption) and leads directly to the design of the industrial electrolyte. Do the selection criteria call out a suitable material that will function as an oxygen-evolving anode, i.e., in the candidate electrolyte what is the emf series and what are the overvoltages associated with various suspected anodic processes?

Tests have begun to examine the technical feasibility of direct electrolysis of chromate sludge (9). What has been demonstrated thus far is that it is possible to design a melt that is ionic and will sustain faradaic processes as evidenced by the presence of oxygen which was detected only in response to the passage of electric current. When the melt was simply heated to $1550^{\circ} \mathrm{C}$ and held at this temperature for several hours, no oxygen was detected. This observation is extremely important, as many molten oxides containing substantial amounts of transition-metal oxide, e.g., ferrites and chromites, are known to be electronic conductors. In such melts, electrochemical processing is impossible. This experiment then demonstrates that by judicious choice of melt composition one can dissolve transition-metal oxides and retain ionicity.

Possibly, the cathodic the reaction was the reduction of iron and chromium from higher to lower valent forms, as for example,

$$
\mathrm{Cr}^{6+}+3 \mathrm{e}^{-} \rightarrow \mathrm{Cr}^{3+} \text { and } \quad \mathrm{Fe}^{3+}+\mathrm{e}^{-} \rightarrow \mathrm{Fe}^{2+} \text {. }
$$


More work is necessary to reveal the true nature of the cathodic reaction. Stepped potential chronoamperometry and electrochemical impedance spectroscopy are the electrokinetic techniques this author recommends for such a study. If the reactions proposed above in fact do occur, then direct electrolysis in molten oxides is a means to immobilize the toxic hexavalent chromium ion. Clearly, from a commercial standpoint it would be desirable to be able to extract the chromium as metal. By changes in electrolyte chemistry and processing conditions, e.g., current density and temperature, it may be possible to reach this goal.

\section{References}

1. D.R. Sadoway, "The Electrochemical Processing of Refractory Metals," JOM, July (1991), 15-19.

2. Compilation of Air Pollutant Emission Factors, Vol. 1, Stationary Point and Area Sources, Sections 7.2 and 7.5, EPA AP-42, Sept. 1985.

3. J.F. Elliott, "Energy, the Environment, and Iron and Steel Technology," in Energy and the Environment in the 21 st Century, ed. J.W. Tester, D.O. Wood, and N.A. Ferrari, MIT Press, Cambridge MA, 1991, pp. 373-382.

4. H.W. Paxton, "The Post-2000 North American Iron and Steel Industry," in Proceedings of the Sixth International Iron and Steel Congress, Vol. 1, ISIJ, Tokyo, 1990, pp. 17-27.

5. "Electrochemical Extraction of Metals," The MIT Report, 19 (1) (1991), 1.

6. "Environmentally Sound Electrochemical Method Produces High Purity Metals," Materials and Processing Report, 6 (6) (1991), 1.

7. R. H. Aiken, "Process of Making Iron from the Ore," U.S. patent no. 816,142, March 27, 1906.

8. D.R. Sadoway, "A Materials Systems Approach to Selection and Testing of Nonconsumable Anodes for the Hall Cell," in Light Metals 1990, C.A. Bickert, editor, TMS, Warrendale PA, 1990, pp. 403-407.

9. D.R. Sadoway, "Metallurgical Electrochemistry in Nonaqueous Media," Proceedings of the Elliott Symposium on Chemical Process Metallurgy, P.J. Koros and G.R. St. Pierre, editors, ISS, Warrendale PA, 1991, pp. 189-196.

10. D.R. Sadoway, inventor, Massachusetts Institute of Technology, assignee, "Electrolytic Production of Metals Using Consumable Anodes," U.S. patent no. 5,185,068, February 9, 1993.

11. J.N. Hryn and D.R. Sadoway, "Cell Testing of Metal Anodes for Aluminum Electrolysis," Light Metals 1993, S.K. Das, editor, TMS, Warrendale PA, 1993, pp. 475-483.

12. D.R. Sadoway, "New Opportunities for Waste Treatment by Electrochemical Processing in Molten Salts," in Metals and Materials Waste Reduction, Recovery and Remediation, K.C. Liddell, R.G. Bautista, and R.J. Orth, editors, TMS, Warrendale, PA, 1994, pp. 73-76.

13. Scott Senturo, New Jersey Department of Environmental Protection, Trenton, NJ, private communication, September 28, 1994. 